\title{
SPECIAL SECTION
}

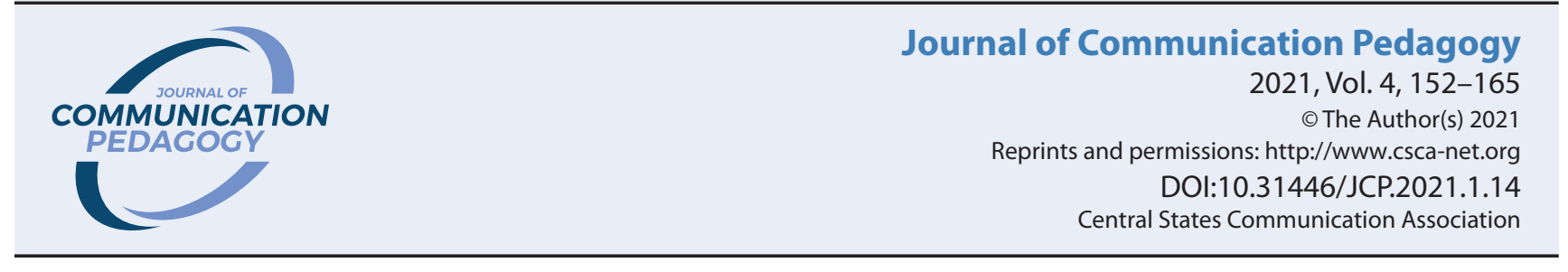

\section{Learning About Metadata and Machines: Teaching Students Using a Novel Structured Database Activity}

\author{
Andrew lliadis $\oplus^{\text {, Tony Liao }}{ }^{\oplus}$, Isabel Pedersen ${ }^{\oplus}$, and Jing Han $\odot$
}

Keywords: metadata, structured data, activity, human-machine communication, machine teachers

\begin{abstract}
Machines produce and operate using complex systems of metadata that need to be catalogued, sorted, and processed. Many students lack the experience with metadata and sufficient knowledge about it to understand it as part of their data literacy skills. This paper describes an educational and interactive database activity designed for teaching undergraduate communication students about the creation, value, and logic of structured data. Through a set of virtual instructional videos and interactive visualizations, the paper describes how students can gain experience with structured data and apply that knowledge to successfully find, curate, and classify a digital archive of media artifacts. The pedagogical activity, teaching materials, and archives are facilitated through and housed in an online resource called Fabric of Digital Life (fabricofdigitallife.com). We end by discussing the activity's relevance for the emerging field of human-machine communication.
\end{abstract}

This manuscript reports on a multi-sited application of a novel pedagogical activity for teaching communication students about metadata (and more broadly about the traces left by digital machines). The activity focuses on teaching students how to collect digital media artifacts about a particular topic (in our case, the topic was augmented reality), how to categorize and label the digital artifacts using a metadata system, and how to present the results of their work in the form of a curated digital archive. This study explores how to build student digital literacy (Tham et al., 2021) around data, metadata, and

Special thanks to Luke Heemsbergen for providing helpful feedback on this project.

Andrew Iliadis, Temple University, Philadelphia, PA

Tony Liao, University of Houston, Houston, TX

Isabel Pedersen, Ontario Tech University, Toronto, Ontario

Jing Han, Temple University, Philadelphia, PA

CONTACT: andrew.iliadis@temple.edu 
categorization, with activities designed to help students understand and reflect on their communication with and through digital machines. First, we describe why teaching metadata is an important topic for communication pedagogy, before presenting our aims and objectives for the activity. We then present a metadata activity where students actively found artifacts and categorized metadata in a real working database, and report on some of the student learning outcomes and preliminary reflections on the activity.

\section{Teaching Metadata}

Metadata, defined broadly as a set of data that describes and gives information about other data (data about data), play a fundamental role in human interactions with machine processes (Zeng \& Qin, 2016). Metadata are important for how they are created, what they can tell us about data, how they are utilized, and can be a useful tool for learning about how data gets used by machines. Data scholars have argued for the need to foreground data creation processes and data infrastructure literacy as a critical component for understanding data (Gray et al., 2018; Iliadis \& Russo, 2016). At their core, metadata are ways to talk about the nature of digital objects once specific aspects of the world have been digitized. These metadata can be orchestrated and structured in such a way as to help people make sense of things through context and, thus, metadata can be powerful tools for building knowledge and increasing literacy, particularly about new and emerging media/communication phenomena. A deeper understanding of metadata is a prerequisite for understanding perceptions of human-machine communication (HMC) and the ways that human interactions with machines produce and reproduce digital traces.

While it is possible for metadata to be constructed actively, much of what gets generated is passive in that humans are often unintentionally creating metadata through their digital actions all the time (e.g., chatting with an automated customer assistant or using a messaging app). Because people tend to be less aware of the automatic data processes of passive metadata creation, we believe that assigning active metadata construction as a pedagogical activity can help increase awareness of metadata and shed light onto the power that metadata have for adding context and meaning to data. Active metadata construction can also cause students to confront metadata directly, and hopefully serve as a reflexive tool/prompt for learning about different HMC contexts and promoting digital literacy. We believe that metadata can be an effective tool in increasing students' data literacy around HMC through the examination, contribution, and curation of metadata activities.

Our proposed metadata making activity (building and organizing metadata about digital objects) involved archiving digital artifacts in a machine-assisted learning environment and then presenting the results there in a curated collection (material for the project in our case was centered on the topic of augmented reality; see Armfield et al., 2018; Heemsbergen et al., 2021; Liao, 2012; Pedersen, 2005). Our learning objective was to teach students about the value and logic of structured metadata and to see if the students could successfully complete an activity that required them to accurately process metadata through data entry. In preparing our metadata activity, we tried to address the following questions about teaching HMC topics, originally posed by A. Edwards and C. Edwards (2017a, p. 191): (1) "Do the affordances of the selected technology align with your learning objectives?" (2) "What factors should you consider before using machine sources in the classroom?" and (3) "What could be gained by having students try to teach machines?" In our case of metadata modeling, answering these questions forced us to separate the differences between several types and ways of teaching metadata, including using metadata modeling to identify distinctions between collections for professional use in institutions, collections for personal use by people in their everyday lives, and collections by researchers to provide 
evidence (Meghini, 2015). We decided that the use of an interactive activity facilitated using a piece of research software would be ideal, rather than through an enterprise product or personalized website.

\section{Teaching Metadata Using Fabric}

In thinking about what affordances of technology would align with our learning objectives, we decided that using a machine-assisted teaching environment would help with teaching and promoting metadata literacy using case/context-based examples that promote reflexivity. The activity was facilitated through Fabric of Digital Life (Fabric), an online research collaborative and cultural analytics database. Fabric, first, tracks and stores metadata about the emergence of embodied computing platforms through digital media archiving (Iliadis \& Pedersen, 2018; Pedersen \& Iliadis, 2020). Then, it can serve as an interaction partner in educational settings through interactional videos, interfaces, and cataloguing (fabricofdigitallife.com). We thought Fabric would be a useful machine-assisted interaction partner and tool for students to learn about metadata/structured data. Fabric uses CollectiveAccess, an opensource collections management and presentation software. Fabric's metadata categories meet the Dublin Core metadata standard (Caverlee et al., 2018) with some additional customized visualizations (avatars, analytics, etc.) and metadata fields for storing and describing digital media artifacts (Figure 1). A previous project (Duin \& Pedersen, 2020) used Fabric in the service of pedagogy and produced supporting resources that instructors can use across multiple disciplines to build digital literacy through metadata archiving on Fabric, and these are also located on the Fabric site (sites.google.com/umn.edu/ buildingdigitalliteracy/home). The materials include (1) a metadata spreadsheet for entering the data, (2) instructional videos describing each of the metadata categories, and (3) guides on how to start a collection (Figure 2).
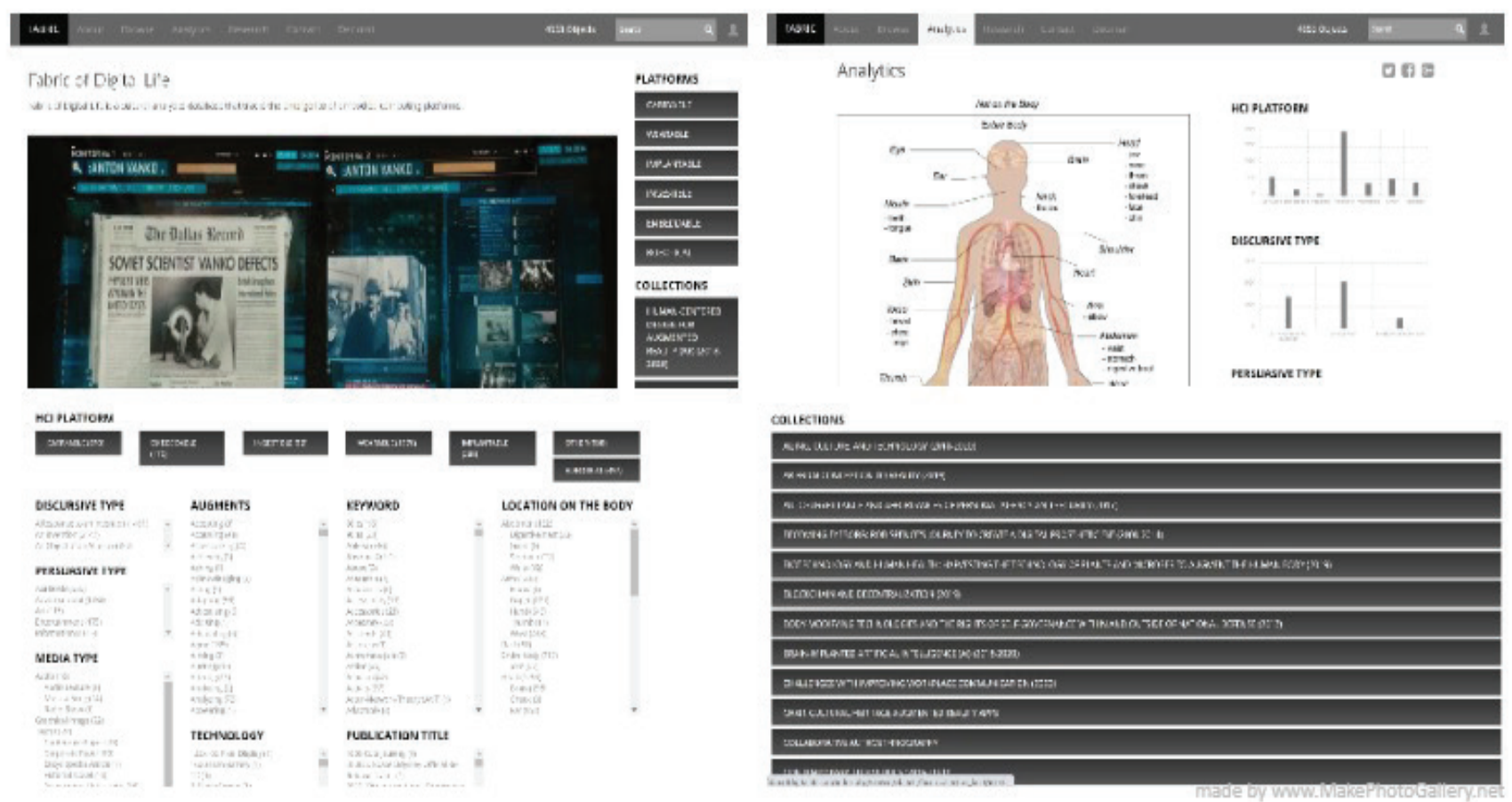

FIGURE 1 Various Fabric Interfaces (fabricofdigitallife.com). 

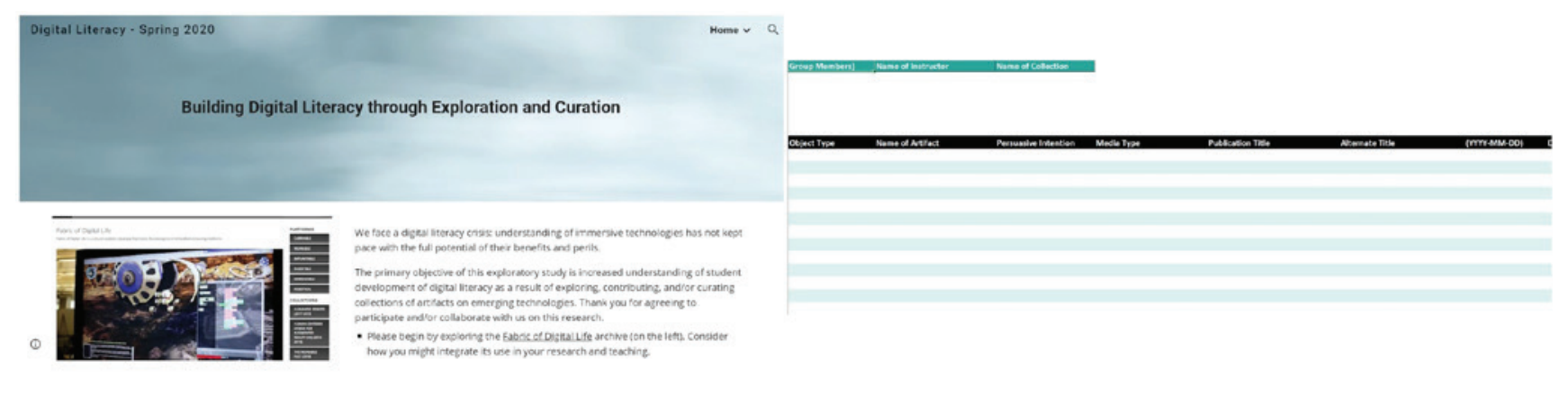

\section{FABRIC'S METADATA GUIDE}

Prepared by: Sharon Caldwell

Date:July 2019 (version 2)

For more information, please see our video instructional guides at:

https://decimal.screencasthost comfabric

ARTIFACT TYPE

When creating a new submission, you must first determine your artifact's type or form:

- Image (for photographs or still images without text)

- Merriner Imama ifrur videnet no

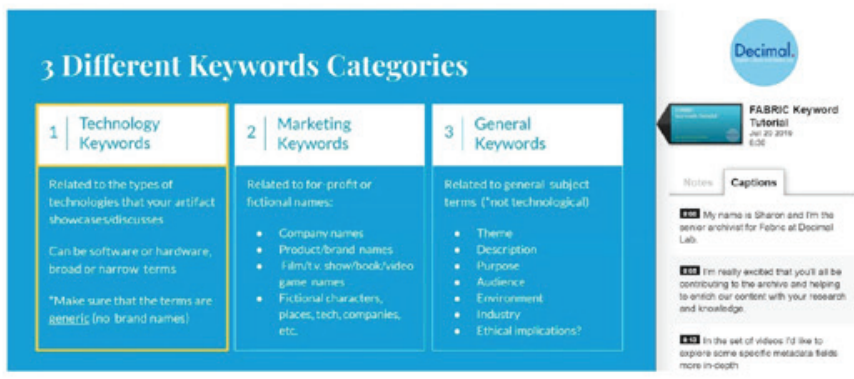

FIGURE 2 Fabric's Metadata Learning Materials (Duin \& Pedersen, 2020).

Fabric's metadata organizing allows students to map out how HMC platforms (e.g., wearables, robots, etc.) are ideationally conceptualized, physically concretized, and socially contextualized within an objectcentered network (Fordyce et al., 2016). Students can enter metadata for the digital objects they want to add to Fabric, thus creating a linked map to explore shifting narratives and production trajectories through their connection to digital media artifacts such as patents, news releases, instructional videos, and policy documents. For example, students might enter the search term "smart watches" which would bring hundreds of interactive media results (e.g., videos, text, etc.) that future users could begin browsing via tagged metadata links in the objects for additional keywords (e.g., health, communication, heart rate, social media, etc.), producing complex timelines of concepts in the field. This iterative process allows students to see how metadata may be used to read certain HMC topics.

In this way, Fabric can be used to construct learning and teaching activities and facilitates the connections between learners and between learners and instructors (Duin \& Pedersen, 2020). Therefore, a networked learning and teaching environment is co-created where students can add metadata information and thus serve as teachers themselves. Within this environment, students can contribute their own metadata to help future students recognize and reveal information that might be hidden due to preconceived assumptions regarding the intentionality and utility of emerging technologies and their corresponding innovation hype. Instructors can promote learning by inviting students to engage and join the discourses by identifying the language of emergence through metadata, schematizing levels of data abstractions, and competing motives into a coherent narrative, and by forming a digital humanistic framework (Pedersen \& DuPont, 2017). 


\section{Activity Description}

Our activity was conducted twice over the course of a single communication class at two large public universities in the United States. There were 19 students in one class and 19 in the other for a total of 38 students. In thinking about what factors to consider before using machine sources in the classroom, we decided that metadata literacy should be built into a machine-assisted teaching environment, and that using the Fabric instructional materials such as videos, spreadsheets, texts, and interfaces would be needed for the activity. We guided students through this process as they worked with the materials on Fabric. The steps for our activity are presented below (steps 1-4 and 8 are completed in Fabric):

1. Register for a Fabric account at fabricofdigitallife.com.

2. Read the information about submitting artifacts on Fabric.

3. Review the metadata guide.

4. Watch the video guides.

5. Use the provided spreadsheets for labeling metadata.

6. Gather and save digital objects related to a chosen theme.

7. Enter metadata for those objects into the spreadsheets.

8. Submit the spreadsheet metadata to Fabric for processing.

Students were first instructed to review the interactive videos and texts in Fabric concerning how to make an account and start a new form for adding digital objects, along with material explaining what each of the metadata categories stands for. Table 1 contains the description of the metadata categories and their definitions that students had to review (steps 2-4) through the Fabric materials prior to starting the activity. After reviewing and interacting with the Fabric learning materials, students then were required to collect digital artifacts, downloading their files into a folder (step 6), and label them using metadata (step 7) for processing and then enter the data into Fabric (step 8). The aim was to have students successfully understand each of these metadata categories and relationships with the goal/objective of having students then produce suitable and appropriate metadata examples that they submitted to Fabric. The metadata categories include things like publishing details, persuasive intentions, and keywords.

\section{TABLE 1}

Fabric's Metadata Categories and Their Descriptions

\begin{tabular}{|l|l|}
\hline \multicolumn{2}{|c|}{ Metadata Categories and Descriptions } \\
\hline Object Type & $\begin{array}{l}\text { When creating a new submission, you must first determine your artifact's type or } \\
\text { form: Image (for photographs or still images without text), Moving Image (for vid- } \\
\text { eos), or Text (for articles, patents, blog posts, etc.). }\end{array}$ \\
\hline Name of Artifact & $\begin{array}{l}\text { Refers to the title of your article, video, or image (e.g., "Iron Man - Designing and Test- } \\
\text { ing the Mark II Gauntlets" or "NeuroPace: How the RNS System Works"). }\end{array}$ \\
\hline Persuasive Intention & $\begin{array}{l}\text { Refers to your artifact's intention and purpose (e.g., advertisement, information, } \\
\text { entertainment, etc.). }\end{array}$ \\
\hline Media Type & $\begin{array}{l}\text { Refers to the artifact's specific media format. Each subtype is indented under the } \\
\text { broader category. It is best to select a narrower category to describe your artifact. } \\
\text { If none of the subtypes fit your artifact, then you can choose the broader category } \\
\text { (e.g., corporate video, news broadcast, feature film, etc.). }\end{array}$ \\
\hline
\end{tabular}




\begin{tabular}{|c|c|}
\hline Publication Title & $\begin{array}{l}\text { Refers to the name of the newspaper, magazine, journal, or blog (e.g., TechCrunch, } \\
\text { The New York Times, IEEE Spectrum) OR the name of the film/TV show/video game/ } \\
\text { book (e.g., Iron Man, Black Mirror), not the title of the article. If it's a corporate video, } \\
\text { you can leave this category blank. }\end{array}$ \\
\hline Publication Date & $\begin{array}{l}\text { Refers to the date that your artifact (article, video, or image) was published (YYYY- } \\
\text { MM-DD). }\end{array}$ \\
\hline Description & $\begin{array}{l}\text { A short description of your artifact that gives it context. For academic articles or } \\
\text { patents, you can post the abstract. For journalistic articles, you can either copy and } \\
\text { paste the introductory paragraph, or (if you're feeling ambitious), summarize the } \\
\text { article yourself in a short paragraph or two. An ideal description would include what } \\
\text { the product/invention/service/film is, its intention or use(s), some key technological } \\
\text { components, and why it is important. }\end{array}$ \\
\hline Technology Keywords & $\begin{array}{l}\text { Refers to all the different technologies that your artifact discusses or showcases. This } \\
\text { can include broader technology categories (e.g., Artificial Intelligence (AI), Smart- } \\
\text { glasses, Smartphone Applications, Holographics, Facial Recognition, Spatial Comput- } \\
\text { ing, Fitness Trackers, etc.) as well as the more 'granular' technologies (e.g., Batteries, } \\
\text { Light Emitting Diodes (LED), Radio Frequency Identification (RFID), 3D Printing, Tem- } \\
\text { perature Sensors, Cameras, etc.). This category is only for generic technological terms } \\
\text { (e.g., Operating System (OS), Wireless Connectivity, Heads Up Displays (HUD), etc.). } \\
\text { Note: specific brands or trademarked names of technologies (e.g., Android KitKat, } \\
\text { Bluetooth, Google Glass) belong in Marketing Keywords) }\end{array}$ \\
\hline Marketing Keywords & $\begin{array}{l}\text { Refers to anything that is marketed for profit: the names of companies (corpora- } \\
\text { tions, start-ups, etc.) as well as their products (Google Glass, Muse Softband). It also } \\
\text { includes the names of films (e.g., Blade Runner, Terminator 2) TV shows (e.g., Black Mir- } \\
\text { ror, Westworld), video games (e.g., Deus Ex, Cyberpunk 2077), books (e.g., Do Androids } \\
\text { Dream of Electric Sheep, Neuromancer), fictional characters (e.g., T-1000, Tony Stark), } \\
\text { fictional technologies (e.g., Mark II, Universal Translator), fictional places (e.g., The } \\
\text { Oasis, The Metaverse), and fictional companies (e.g., Skynet). For products, include } \\
\text { the name of the company along with the name of the Product (e.g., Fitbit Versa). } \\
\text { For example, if you are archiving a video about the "Vuzix Blade Augmented Reality } \\
\text { Smartglasses," your Marketing Keywords would be: Vuzix (name of company) and } \\
\text { Vuzix Blade (name of product). }\end{array}$ \\
\hline General Keywords & $\begin{array}{l}\text { Refers to general words that help further categorize the artifact and the subject(s)/ } \\
\text { concept(s) it discusses. This can include broad terms (e.g., Fashion, Medical, Ethics) } \\
\text { or narrower terms (e.g., Shirts, Parkinson's Disease, Privacy, etc.). It can also include } \\
\text { descriptions of the product (e.g., Comfort, Stylish, Immersive). }\end{array}$ \\
\hline Classification & $\begin{array}{l}\text { An Invention: Select this if your artifact discusses or announces the creation of a } \\
\text { device/product (e.g., a commercial for the Samsung Galaxy Gear). This includes } \\
\text { company concept or launch videos, demonstrations from the creator, news releases } \\
\text { written by the company/inventor, patents, etc. A Response to an Invention: Select this } \\
\text { if your artifact features commentary about an invention (e.g., Forbes discussing the } \\
\text { new Apple Watch Series 4). Magazine or newspaper articles, news videos, and blog } \\
\text { posts typically belong in this category, unless it is the inventor writing about the } \\
\text { product (e.g., someone from Apple writing a guest post on Forbes about the new } \\
\text { Apple Watch Series 4). In this case, it would be classified as 'An Invention'. An Object } \\
\text { of an Allusion: Select this if your artifact is a snippet from popular culture or fiction } \\
\text { (e.g., film trailers, clips from movies or TV shows). These are useful to archive because } \\
\text { inventors will sometimes allude to pop culture by saying something like, "I was } \\
\text { inspired to create this device after watching Star Wars/Batman/Minority Report, etc." }\end{array}$ \\
\hline Related Items & Any related items in the database. \\
\hline
\end{tabular}




\begin{tabular}{|c|c|}
\hline Allusion or Response & $\begin{array}{l}\text { Does your artifact refer to any other inventions, responses to inventions, or objects } \\
\text { of allusions in the archive? For example, if you are archiving a magazine review of } \\
\text { the Oculus GO VR headset, you would include the primary Oculus GO advertisement } \\
\text { here. If your artifact references any similar inventions (e.g., an article about North's } \\
\text { Focals mentions Google Glass) or alludes to pop culture (e.g., the concept video for } \\
\text { an AR heads-up display alludes to Tony Stark's suit in Iron Man), include them here. }\end{array}$ \\
\hline $\begin{array}{l}\text { Names of Creators, Contribu- } \\
\text { tors, Publishers }\end{array}$ & $\begin{array}{l}\text { Refers to any individuals or organizations (companies, universities, research groups, } \\
\text { etc.) who helped create, contribute to, or publish your artifact as well as the technol- } \\
\text { ogy being advertised or discussed. Author(s): Refers to the name(s) of the person/ } \\
\text { people/company who wrote the article or created the video. For films, it would be } \\
\text { the director. Contributor(s): Refers to any other person who is mentioned in the } \\
\text { artifact, but is not the main creator. This could be editors, experts, or researchers in } \\
\text { the field, as well as any relevant universities/research labs/institutions/organizations. } \\
\text { Publisher(s): Refers to the name of the company or institution that published the } \\
\text { artifact (e.g., Brown University, Vice Media, Springer Nature Publishing). This may be } \\
\text { different than the publication title. For example, CNET is published by CBS Interactive } \\
\text { Inc. Look for the copyright symbol at the bottom of websites. For films, include the } \\
\text { name of the production company (e.g., Warner Brothers, Marvel Studios). }\end{array}$ \\
\hline Location on Body & $\begin{array}{l}\text { Refers to where on the body the device is meant to be worn, embedded, or } \\
\text { implanted. Think about which part(s) of the body is being augmented: If it's an } \\
\text { Ingestible, it would typically be Digestive Tract. If it's Robotical, you would classify it } \\
\text { as the Entire Body (referring to the robot itself). If it's in the Other category (e.g arti- } \\
\text { ficial intelligence algorithms that aren't associated with a specific device, or ambient } \\
\text { technologies like smart sensors for homes), it will likely be classified as Not on the } \\
\text { Body. If it's Carryable, it will likely be on the Hand. For Wearables, it could be the Wrist } \\
\text { (for smartwatches), the Eyes (for AR/VR headsets or smartglasses), the Entire Body or } \\
\text { the Torso (for smart clothing), etc. }\end{array}$ \\
\hline Augment Keywords & $\begin{array}{l}\text { Refers to the ways in which the product or technology helps to augment the human } \\
\text { body. Consider things such as: how the product enhances human capacity, actions } \\
\text { the person performs while interacting with the technology, and what the product } \\
\text { or technology helps facilitate (e.g., Walking, Exercising, Working, Communicating, } \\
\text { Creating, Imagining, Engaging, Expressing, Feeling, Learning, Living, etc.). Write it as a } \\
\text { present tense action verb (ending in 'ing'). }\end{array}$ \\
\hline Use/HCI Platform & $\begin{array}{l}\text { Refers to the way that the technology being discussed in your artifact is intended } \\
\text { to interact with the human body. Carryable: Is it meant to be carried around (e.g., } \\
\text { smartphones or tablets)? Wearable: Is it meant to be worn somewhere on the body } \\
\text { (e.g., smartwatches, LED dresses, Brain-Computer Interfaces that use EEG sensor } \\
\text { caps)? Embeddable: Is it meant to be embedded into the body (this refers primarily } \\
\text { to prosthetics that are not explicitly implants; e.g., prosthetic legs, bionic hands)? } \\
\text { Implantable: Is it meant to be implanted in the body, typically through surgical } \\
\text { means (e.g., pacemakers, Brain-Computer Interfaces such as Elon Musk's Neuralink, } \\
\text { cybernetics, sensors that transhumanists or biohackers/grinders put under their skin, } \\
\text { etc.)? Ingestible: Is it meant to be consumed internally (e.g., a digital pill)? Robotical: } \\
\text { Is it a standalone robot that is physically separate from the human body altogether } \\
\text { (e.g., humanoid robots, social and companion robots, mobile manipulator robots)? } \\
\text { Other: Does it not fit into any of the above categories (e.g., artificial intelligence algo- } \\
\text { rithms or systems that are not incorporated into robots or other HCl technologies } \\
\text { (IBM's Project Debater), smart home systems, the internet of things and connected } \\
\text { devices, personal assistants like Apple's Siri, self-driving cars)? }\end{array}$ \\
\hline Source/Web & $\begin{array}{l}\text { Refers to the web address of the artifact. Copy and paste the link to your video, arti- } \\
\text { cle, or image here. }\end{array}$ \\
\hline
\end{tabular}


Because the Fabric database focuses on embodied computing technologies, our activity asked students to label individual media artifacts related to applications in one embodied computing area. In our example, students focused on the topic of augmented reality and policing (Figure 3), while also focusing on one of three geographic locations (USA, UK, China). Students were placed into three groups, with a focus on one of the three different geographic areas to ensure that they found different assets but also to capture a wider range of artifacts. Students then searched for digital artifacts (e.g., articles, patents, videos, etc.) on the web relating to augmented reality and policing in their given geographic area. Most of the students conducted Google searches using several variations of keywords relating to their topics and saved their digital artifacts into folders on their computers. After finding their artifacts, students then began to create all the metadata for each of their found digital objects in the metadata spreadsheet provided by Fabric. For example, students had to enter the information for each of the categories listed in Table 1 for each media artifact, and these included naming the object and media types, publication dates and titles, persuasive intention, various keywords, and so forth. Students then handed in their spreadsheets after filling in all the metadata for their collected digital media artifacts, so that it could be entered into Fabric. After conducting the metadata exercise, students were asked to comment and reflect on the metadata categories as well as instances where they had difficulty categorizing certain artifacts using the predefined categories. Below is a shortened description of the activity provided to students (Table 2 and Figure 3).

\section{TABLE 2}

Activity Description Provided to Students

\section{Activity}

Collectively we will be working on creating a curated collection for a digital database called "Fabric." Fabric is a cultural analytics database that tracks the emergence of embodied computing platforms. We will be contributing to a very important collective resource about embodied computing.

Outputs: 1) Class Research - Finding artifacts about our topic for Fabric - Each person is responsible for finding news articles, videos, press releases, entertainment media, and any other public artifact that talks about a particular topic related to AR. We will also post these onto a collective document to minimize redundancies. 2) Class Research Coding the artifacts and entering the metadata for Fabric - After we compile a list of artifacts, each one of you will be responsible for coding the artifacts and entering the metadata for submission to Fabric. Our entries will then be indexed and appear in the Fabric database/website for other people to search. Write a summary of your experience and reflect on what you did.
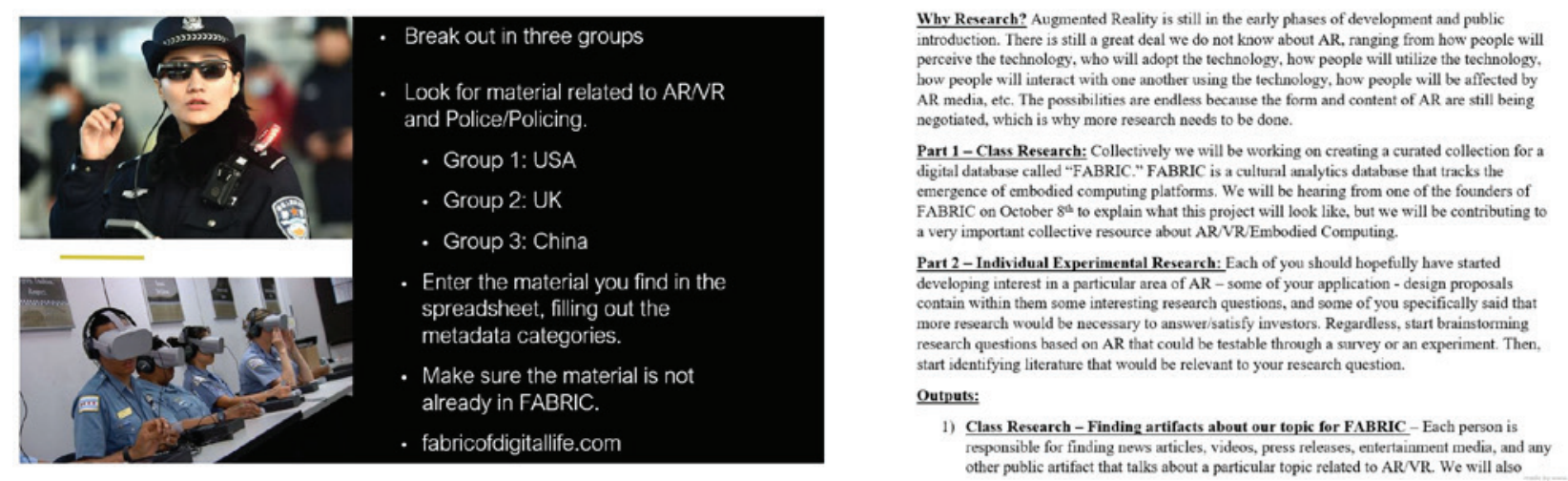

FIGURE 3 Activity Slides Shown to Students. 


\section{Outcomes of the Fabric Activity}

This activity was simultaneously an exercise in learning the metadata language of machines, finding artifacts to apply that language to, and ultimately placing those artifacts into the machine database using that language. By actually placing their artifacts and corresponding metadata into the database for future search queries, students were able to see how metadata functions as a real-world activity. We found that upon completing the activity, students were able to identify several interesting metadata examples. We reviewed the material provided in the submitted examples to see if they satisfied and matched with the criteria listed in the metadata categories and descriptions. The material showed evidence that the students were able to successfully apply their knowledge of metadata into filling the categories that were required of them. For example, the object types were described (text, video, interactive resource, etc.), the names of the artifacts that they found were produced (titles, etc.), the persuasive intentions of the artifacts were labeled (information, advertisement, entertainment, etc.), the media type was recorded (YouTube Clip, Newspaper Article, etc.), publication dates and titles, descriptions of the artifacts, and various keywords, among other metadata categories.

We can offer some preliminary reflections from this activity. First, students seemed to have adequately grasped the nature of metadata and its processing based on their experiences with the Fabric machineassisted learning environment. Focusing on HMC, students developed their conceptualization around AR technologies, considering how AR is ontologized into specific abstract categories and taxonomies. In this stage, students imagined how AR might be conceptualized as a media technology. This stage involved creating technology keywords related to aspects of AR's ontological categorizations (things like heads-up display, visual interface, smart glasses, batteries, etc.). The conceptual design of AR as an embodied computing device was emphasized to locate the contours and abstract ideations of what AR media are supposed to include and how they are taxonomized. The students conducted systematic reviews of how AR is conceptualized in research and production from a discursive perspective, analyzing and then labeling media artifacts relating to the conceptualization of design.

Second, students focused on the concretization of their concepts by focusing on how AR concepts are embodied in industry, market, and regulatory forces (Heemsbergen et al., 2021 aided our reflections on the activity and how AR is conceptualized). This was done through the creation of marketing metadata keywords that included things like company and product names. Concretization considers how AR concepts are reified into production and market materializations. This step takes the abstract categories that students developed in the ontologizing of AR technologies and applies them into groups of existing companies, products, domains, and marketing materials. These are the materials that mediate AR conceptualizations into embedded and embodied practice, highlighting the implementation of concepts in the real world. Students observed actual companies that build AR for policing, as well as the names of those AR products. They also identified government, intelligence, policing, and security organizations that use these AR conceptualizations in concrete practices.

Beyond the tangible artifacts they found, their reflections on the exercise were also enlightening. One common theme was that students talked about how breaking down the artifact in a systematized way demystified some of the power of the database. Some talked about how they now understood how these decisions were made, and how humans were making these determinations. Having the experience of curating data helped them better understand what they see when they utilize the database and see the search results presented. Another common theme was a feeling that they were constrained by the metadata 
codes, not because they were incomplete, but they could only distill the features of the artifacts without necessarily capturing their full meaning. For example, while the system allowed them to annotate the persuasive intention and allusion, it may not have captured how positive a particular video was toward the idea of augmented policing, or how they presented it as a necessity. It also illustrated to students how certain metadata categories would be more useful as a sorting function, given that certain classification categories would place various dissimilar and incommensurate artifacts in the same category just because it was an advertisement or talked about a particular device.

Lastly, students turned from concretization to contextualization by imagining AR media and its intended public debate but also how AR media confront continued social and cultural appropriations. This was done through identifying general keywords related to concretized AR media objects. Such keywords include those related to augmenting (e.g., purchasing, surveilling, policing, etc.). Contextualization is where detailed information about HMC and policing practices was included, describing how users like police, government, military, and security companies are employing HMC in the field for specific cases and purposes (e.g., to combat illegal immigration, etc.). This stage is where the different social contexts are identified, and in the context of our class activity, students identified different cultural contexts related to AR and policing in the UK, USA, and China. Students also imagined the use of AR technologies in these contexts, hinting at potential uses and futures.

\section{Discussion}

One important factor in data literacy is to gain a level of reflexivity about data, particularly the interrelationships between how data are found, refined, and made (Armfield et al., 2019; Duin et al., 2019; Duin \& Pedersen, 2020; Duin et al., 2021). Teaching students this requires building in interactive experiences with data and encouraging them to reflect on the process of refining and producing data. Following an HMC focus on ontologizing and laying bare "communication with digital interlocutors" (Fortunati \& Edwards, 2020, p. 7), we found that Fabric promotes the pedagogical experiencing of machinic content while foregrounding the human-centered design of interaction technologies like AR (Armfield et al., 2019). Specifically, the Fabric interface highlights the data ontologies and their ontological shifts (Iliadis, 2018, 2019) in HMC devices (Banks \& de Graaf, 2020; A. Edwards, 2018; Guzman, 2020) by categorizing and making searchable/retrievable information about the technologies, their histories, and varieties of social utilities and functions. This type of activity offers a pedagogical opportunity where students can begin by creating their own data to input into a machine, rather than taking a top-down approach of inputting data into a machine and delivering that to the student-students thus become active participants in the teaching/learning cycle in both directions.

We think that Fabric's affordances generally aligned with the learning objectives for our activity. Fabric contains the necessary visualizations and interaction capabilities that allow students to learn about metadata in a uniform and self-paced learning environment. As a machine-assisted teaching tool, Fabric seemed to be able to promote reflexivity and literacy about metadata through its affordances that students were able to take advantage of, such as the avatars and videos. Second, we think that Fabric contains several factors that are needed in any machine teaching scenario, including the opportunity for self-pacing and self-directedness, along with clear visualizations and instructions with both audio and visual material. Most importantly, examples are included to allow students to visualize their future work. Students were able to visualize the metadata through analytics visualizations before conducting 
their own projects. In this way, Fabric seemed to contain several of the necessary tools, processes, and activities that were required. Lastly, Fabric shows what could be gained by having students try to teach machines. Part of Fabric and the associated activity is designed around student-led contributions to Fabric's content by way of processing students' metadata projects into Fabric. Fabric is essentially learning from the students, and the student-submitted metadata will later serve as material for future learning done on and through Fabric.

\section{Conclusion}

$\mathrm{HMC}$ is an emerging subfield in communication that focuses on technologies that are designed to enact the role of communicator (e.g., virtual assistants, robots, virtual avatars, etc.) and on meaning-making processes that occur in everyday encounters with technology as a communicative subject (C. Edwards et al., 2019; Guzman, 2018; Jones, 2014). Of particular interest to HMC scholars is HMC's similarity to interpersonal communication, and more specifically approaches toward computational interpersonal communication (C. Edwards et al., 2020; Gunkel, 2016; Westerman et al., 2020) and understanding the various ways in which people communicate with machines as social robots (Gehl \& Bakardjieva, 2016). For example, such interpersonal scenarios might include people engaging in dialogue with Twitter bots or virtual assistants like Alexa. A second interest of HMC scholars is in HMC's similarities to mass media using algorithms, artificial intelligence, and automation for communicative meaning-making (Gunkel, 2012; Guzman \& Lewis, 2020; Lewis et al., 2019).

Moving beyond similarities with interpersonal and mass media approaches, there are many opportunities to invert the common ways that scholars think about machine education. HMC research into education has focused a lot on the delivery of data $\rightarrow$ to machine $\rightarrow$ to student direction (for example, in online learning environments where students are seen as passive receivers of information, or when students interact with a robot), which is only one direction and starting point. Switching the direction to student $\rightarrow$ creating data $\rightarrow$ inputting data machines could also be important. We think that Fabric promotes this second direction, where students are the ones who begin by creating material and then eventually contributing that material to a machine-assisted learning tool. This type of perspective puts emphasis on the students and their creative capacities to produce materials, and we think that this perspective empowers students in their learning and education.

As communication and educational scholars continue to think about student engagement with machine teachers (e.g., with social robots, avatars, etc.) (Belpaeme et al., 2018; A. Edwards \& C. Edwards, 2017b; C. Edwards et al., 2018), more work is necessary to understand these interactions. Although much of the literature has focused on conceptual and behavioral/experimental approaches to machine teachers/ teaching, machine teachers/teaching also provides opportunities to examine iterative and reflexive ways to promote student understanding of machine-assisted pedagogy in nontraditional learning settings and through synergistic work. In addition to understanding machines as teachers, we argue that it is equally important to provide students with an understanding of how data are created and on what basis they are teaching from. This study offers a hands-on and iterative way of helping students better understand data and metadata as a concept, which could in turn affect their future interactions with machines. 


\section{References}

Armfield, D., Duin, A. H., \& Pedersen, I. (2019). Immersive content in technical communication: A journey mindset. Intercom: Magazine for the Society for Technical Communication, 66(1), 14-17. https:// www.stc.org/intercom/2019/03/immersive-content-in-technical-communication-a-journey-mindset/

Armfield, D., Duin, A. H., \& Pedersen, I. (2018). Experiencing content: Heuristics for human-centered design for augmented reality. In IEEE International Professional Communication Conference (ProComm) (pp. 241-247). IEEE. https://doi.org/10.1109/ProComm.2018.00057

Banks, J., \& de Graaf, M. M. A. (2020). Toward an agent-agnostic transmission model: Synthesizing anthropocentric and technocentric paradigms in communication. Human-Machine Communication, 1, 19-36. https://doi.org/10.30658/hmc.1.2

Belpaeme, T., Kennedy, J., Ramachandran, A., Scassellati, B., \& Tanaka, F. (2018). Social robots for education: A review. Science Robotics, 3(21), 1-9. https://doi.org/10.1126/scirobotics.aat5954

Caverlee, J., Mitra, P., \& Larsgaard, M. L. (2018). Dublin core. In L. Liu \& M. T. Özsu (Eds.), Encyclopedia of database systems (pp. 1248-1251). Springer. https://doi.org/10.1007/978-1-4614-8265-9_894

Duin, A. H., Armfield, D., \& Pedersen, I. (2019). Human-centered content design in augmented reality. In G. Getto, J. T. Labriola, N. Franklin, \& S. Ruszkiewicz (Eds.), Context is everything: Content strategy in technical communication (pp. 89-116). Routledge.

Duin, A. H., \& Pedersen, I. (2020). Building digital literacy through exploration and curation of emerging technologies: A networked learning collaborative. In Publication for the International Networked Learning Conference (pp. 1-20). NLC. https://www.networkedlearning.aau.dk/digitalAssets/ 825/825684_08.-duin---pedersen---building-digital-literacy-through-exploration-and-curationof-emerging-technologies-a-networked-learning-collaborative.pdf

Duin, A. H., Pedersen, I., \& Tham, J. (2021). Building digital literacy through exploration and curation of emerging technologies: A networked learning collaborative. In N. B. Dohn, S. B. Hansen, J. J. Hansen, M. deLaat, \& T. Ryberg (Eds.), Conceptualizing and innovating education and work with networked learning. Springer.

Edwards, A. (2018). Animals, humans, and machines: Interactive implications of ontological classification. In A. L. Guzman (Ed.), Human-machine communication: Rethinking communication, technology, and ourselves (pp. 29-50). Peter Lang.

Edwards, A., \& Edwards, C. (2017a). Human-machine communication the classroom. In M. L. Houser \& A. M. Hosek (Eds.), Handbook of instructional communication instructional: Rhetorical and relational perspectives (pp. 184-194). Taylor \& Francis.

Edwards, A., \& Edwards, C. (2017b). The machines are coming: Future directions in instructional communication research. Communication Education, 66(4), 487-488. https://doi.org/10.1080/03634523. 2017.1349915

Edwards, C., Edwards, A., Albrehi, F., \& Spence, P. (2020). Interpersonal impressions of a social robot versus human in the context of performance evaluations. Communication Education, 70(2), 1-18. https://doi.org/10.1080/03634523.2020.1802495

Edwards, C., Edwards, A., Kim, J., Spence, P. R., de Graaf, M., Nah, S., \& Rosenthal-von der Pütten, A. (2019). Human-machine communication: What does/could communication science contribute to HRI? In J. Kim, A. Tapus, D. Sirkin, M. Jung, \& S. S. Kwak (Eds.), 14th ACM/IEEE International Conference on Human-Robot Interaction (HRI) (pp. 673-674). IEEE. https://doi.org/10.1109/ HRI.2019.8673138

Edwards, C., Edwards, A., Spence, P. R., \& Lin, X. (2018). I, teacher: Using artificial intelligence (AI) and social robots in communication and instruction. Communication Education, 67(4), 473-480. https:// doi.org/10.1080/03634523.2018.1502459 
Fordyce, R., Heemsbergen, L., Apperley, T., Arnold, M., Birtchnell, T., Luo, M., \& Nansen, B. (2016). Things, tags, topics: Thingiverse's object-centred network. Communication Research and Practice, 2(1), 63-78. https://doi.org/10.1080/22041451.2016.1155337

Fortunati, L., \& Edwards, A. (2020). Opening space for theoretical, methodological, and empirical issues in human-machine communication. Human-Machine Communication, 1, 7-18. https://doi. org/10.30658/hmc.1.1

Gehl, R. W., \& Bakardjieva, M. (Eds.). (2016). Socialbots and their friends: Digital media and the automation of sociality. Routledge.

Gray, J., Gerlitz, C., \& Bounegru, L. (2018). Data infrastructure literacy. Big Data \& Society, 5(2), 1-13. https://doi.org/10.1177/2053951718786316

Gunkel, D. J. (2012). Communication and artificial intelligence: Opportunities and challenges for the 21st century. Communication $+1,1(1), 1-26$. https://doi.org/10.7275/R5QJ7F7R

Gunkel, D. J. (2016). Computational interpersonal communication: Communication studies and spoken dialogue systems. Communication +1, 5, 1-20. https://doi.org/10.7275/R5VH5KSQ

Guzman, A. (Ed.). (2018). Human-machine communication: Rethinking communication, technology, and ourselves. Peter Lang.

Guzman, A. (2020). Ontological boundaries between humans and computers and the implications for human-machine communication. Human-Machine Communication, 1, 37-54. https://doi. org/10.30658/hmc.1.3

Guzman, A., \& Lewis S. C. (2020). Artificial intelligence and communication: A HumanMachine Communication research agenda. New Media \& Society, 22(1), 70-86. https://doi. org/10.1177/1461444819858691

Heemsbergen, L., Bowtell, G., \& Vincent, J. (2021). Conceptualising augmented reality: From virtual divides to mediated dynamics. Convergence, online first, 1-17. https://doi.org/10.1177/ 1354856521989514

Iliadis, A. (2018). Algorithms, ontology, and social progress. Global Media and Communication, 14(2), 219-230. https://doi.org/10.1177/1742766518776688

Iliadis, A. (2019). The Tower of Babel problem: Making data make sense with Basic Formal Ontology. Online Information Review, 43(6), 1021-1045. https://doi.org/10.1108/OIR-07-2018-0210

Iliadis, A., \& Pedersen, I. (2018). The fabric of digital life: Uncovering sociotechnical tradeoffs in embodied computing through metadata. Journal of Information, Communication and Ethics in Society, 16(3), 311-327. https://doi.org/10.1108/JICES-03-2018-0022

Iliadis, A., \& Russo, F. (2016). Critical data studies: An introduction. Big Data \& Society, 3(2), 1-7. https://doi.org/10.1177/2053951716674238

Jones, S. (2014). People, things, memory and human-machine communication. International Journal of Media \& Cultural Politics, 10(3), 245-258. https://doi.org/10.1386/macp.10.3.245_1

Lewis, S. C., Guzman, A. L., \& Schmidt, T. R. (2019). Automation, journalism, and human-machine communication: Rethinking roles and relationships of humans and machines in news. Digital Journalism, 7(4), 409-427. https://doi.org/10.1080/21670811.2019.1577147

Liao, T. (2012). A framework for debating augmented futures: Classifying the visions, promises, and ideographs advanced about augmented reality. In Proceedings of 11th IEEE international symposium on mixed and augmented reality (ISMAR '12) (pp. 3-12). IEEE. https://doi.org/10.1109/ISMARAMH.2012.6483982

Meghini, C. (2015). On the logical foundations of digital collections. In C. L. Palmer, A. Isaac, K. M. Wickett, K. Fenlon, \& M. Senseney (Eds.), Digital collection contexts: iConference 2014 workshop report (pp. 1-2). CIRSS. https://core.ac.uk/download/pdf/158298849.pdf 
Pedersen, I. (2005). A semiotics of human actions for wearable augmented reality interfaces. Semiotica, 155(1/4), 183-200. https://doi.org/10.1515/semi.2005.2005.155.1-4.183

Pedersen, I., \& DuPont, Q. (2017). Tracking the telepathic sublime as a phenomenon in a digital humanities archive. Digital Humanities Quarterly, 11(4), 1-13. http://www.digitalhumanities.org/dhq/ $\mathrm{vol} / 11 / 4 / 000344 / 000344 . h t m l$

Pedersen, I., \& Iliadis, A. (Eds.). (2020). Embodied computing: Wearables, implantables, embeddables, ingestibles. MIT Press.

Tham, J. C. K., Burnham, K. D., Hocutt, D. L., Ranade, N., Misak, J., Duin, A. H., Pedersen, I., \& Campbell, J. L. (2021). Metaphors, mental models, and multiplicity: Understanding student perception of digital literacy. Computers and Composition, 59, 1-23. https://doi.org/10.1016/j.compcom.2021.102628

Westerman, D., Edwards, A. P., Edwards, C., Luo, Z., \& Spence, P. R. (2020). I-it, I-thou, I-robot: The perceived humanness of AI in human-machine communication. Communication Studies, 71(3), 393-408. https://doi.org/10.1080/10510974.2020.1749683

Zeng, M. L., \& Qin, J. (2016). Metadata. Neal-Schuman. 